Simon, A., Goto, K., Simon, A., Breed, J., Bianco, S. / Californian Journal of Health Promotion 2018, Volume 16, Issue 1, Pages $73-$ 78 .

\title{
Factors Associated with Food Insecurity and Food Assistance Program Participation among University Students
}

\author{
Ashley Simon ${ }^{1}$, Keiko Goto ${ }^{1}$, Ashley Simon ${ }^{1}$, Jenny Breed ${ }^{1}$, and Stephanie Bianco ${ }^{1}$ \\ ${ }^{1}$ Center for Healthy Communities, California State University, Chico
}

\begin{abstract}
Background and Significance: Food insecurity is an emerging issue among college students. It impacts the lives of many university students due to financial reasons. There is limited information about factors that affect food insecurity in that population. This cross-sectional study aimed to examine factors associated with food insecurity and food assistance program participation among college students. Methods: Food security status was determined using the short form of the USDA's Food Security Survey Module. Results: Out of 116 students, 50 students (43.1\%) were food insecure. Food insecurity was inversely associated with self-reported cumulative grade point averages. Only $24 \%$ of food insecure students participated in food assistance programs. Students who were involved in campus activities were significantly more likely to participate in food assistance programs. University-level policies and programs that help students combat food insecurity need to be considered. Conclusion: The inverse association between food insecurity and academic success indicates the importance of addressing food insecurity issues to foster their academic and professional success among university students. More research on strategies for promoting food assistance programs to college students is warranted.

(C) 2018 Californian Journal of Health Promotion. All rights reserved.
\end{abstract}

\section{Introduction}

Food insecurity is defined as the "limited or uncertain availability of nutritionally adequate and safe foods or limited or uncertain ability to acquire acceptable foods in socially acceptable ways" (Anderson, 1990). In order to be food secure, the foods must be of sufficient variety. Food security also includes having access to nutritious foods or having those foods available for purchase in all neighborhoods.

The United States Department of Agriculture (USDA) has introduced categories for describing a household's food security status ranging from high food security to very low food security (USDA, 2015). The four categories include; high food security, marginal food security, low food security, and very low food security. A person or household's food security status can change suddenly and without warning, as suggested by the descriptions of each category.

Alaimo (2005) developed a conceptual model of food insecurity to depict risk factors, consequences, and coping mechanisms of food insecurity and how those components are reconciled. Food insecurity typically begins with concern over the supply of food, which is referred to as "food anxiety" (Alaimo, 2005). Household risk factors that may influence food insecurity include socio-demographic factors, education and skills, financial resources, health insurance, environment, time, housing, health status, past or present abuse, social support, food skills or capabilities. The most prominent risk factor tends to be financial resources, or lack thereof (Alaimo, 2005; Patton-Lopez, LopezCevallos, Cancel-Tirado, \& Vasquez, 2014).

University students have been identified as one of the susceptible groups to food insecurity (Burns, 2004). Prior research on food insecurity among university students indicates that food insecurity is a significant issue that impacts the lives of many university students, mainly due to financial reasons. In one study $20 \%$ of students reported experiencing anxiety about their food inventory (McLaughlin et al., 2012). The same study showed that students who collected financial aid or were financially independent were more likely to report being food insecure. 
Simon, A., Goto, K., Simon, A., Breed, J., Bianco, S. / Californian Journal of Health Promotion 2018, Volume 16, Issue 1, Pages $73-$

78 .

A cross-sectional study in Oregon revealed that $59 \%$ of university students were food insecure, compared to the food insecurity rate of the general population at $15 \%$ (Burns, 2004). The same study demonstrated that while various food assistance programs may have been available to food insecure students, participation in food assistance programs reached only $27 \%$ of the sample in this study.

Poor academic performance has been identified as one of possible consequences of food insecurity (Alaimo, 2005). Patton-Lopez et al. (2014) found that students who were food insecure were less likely to have a grade point average of 3.1 or higher on a 4.0 scale. Past research suggests that our brains are not fully developed until the late 20s (Giedd, 2004). Thus, university students' food security status may influence cognitive/brain development and their academic performance (Alaimo, 2005; McLaughlin et al., 2012; Burns, 2004).

The objective of this study was to examine factors associated with food insecurity and food assistance program participation among university students in northern California. Specifically, the current study aimed to examine 1) the prevalence of food insecurity among university students, 2) the relationship between food insecurity and academic performance, and 3) the relationship between food insecurity and participation in food assistance programs. There is limited information about factors associated with food insecurity in that population. The current study aims to address food insecurity issues among university students in order to foster their academic and professional success.

\section{Participants}

This study was approved by the Human Subjects Research Committee of [University]. A nonrandom, convenience sampling procedure was used. Participants were students enrolled at [University] during the spring semester of 2015. The survey was administered in four general education nutrition classes. Students were not offered any incentives to participate and were able to withdraw at any time during the survey. The administrator also verbally stated that only students who bought and prepared their own food could participate. A total of 116 students participated in the study.

\section{Survey Instrument}

The survey was composed of 16 items. The use of these items is described below. The authors used these items to acquire information about the participant's demographic background, food security status, and academic performance.

Demographic Information. Participants' age, major, gender identity, race/ethnicity, and year in school were collected. This information was collected to examine whether demographic factors were associated with food security or food assistance program participation. Students' involvement in campus activities such as student clubs/organizations or athletic programs was also examined.

Academic Performance. For the purposes of this study, academic performance was measured by asking participants to self-report their cumulative grade point average (GPA). Since a cumulative GPA is commonly used to assess academic success, it is a universal, easily interpreted measure of that variable.

Food Assistance Program Participation. Participation in food assistance programs was self-reported by study participants. Participants were given a list of food assistance programs such as 1) emergency food from a church, food pantry, food bank, or emergency kitchen, 2) a special Supplemental Nutrition Program for Women, Infants, and Children, 3) Supplemental Nutrition Assistance Program/CalFresh, and 4)Private Organizations. Participants also had the option of citing a program that was not listed.

Food Security Status. Food security status was evaluated using the United States Department of Agriculture (USDA) Six-Item Short Form of the Food Security Survey Module (FSSM). The survey module is designed to measure food insecurity that is a result of a lack of financial capability to purchase food and not for any other reasons (Bickel, Nord, Price, Hamilton, \& Cook, 2000). The validity and reliability of the Six- 
Item Short Form of the FSSM supports the use of it in place of the 18-Item FSSM (Blumberg, Bialostosky, Hamilton, \& Briefel, 1999). Participants scoring 0 to 1 point were classified as high/marginal food security, 2 to 4 points as low food security, and scores 5 to 6 points as very low food security.

\section{Statistical Analyses}

Statistical analyses were completed using the IBM SPSS Statistics Version 22.0 (Armonk, NY: IBM Corp.). Spearman's rho correlation was used to examine the relationship between food security and academic success using the food security score. Food security status was also combined into two categories; food secure and food insecure. Those participants who experienced low food security and very low food security were classified into the food insecure category while those who experienced high or marginal food security were placed into the food secure category. We did not stratify the demographic characteristics by food security status as there were no significant differences in the demographic characteristics between the food security and food insecurity groups.

Chi-square analysis was used to examine the associations between two categorical variables. Multiple linear regression was used to examine the association between food security and continuous dependent variables after controlling for age, gender and race/ethnicity.

\section{Results}

Table 1 and 2 show the demographic characteristics of the participants along with GPA, campus involvement, food security status, and food assistance program participation.

\section{Prevalence of Food Insecurity}

It was found that out of the 116 participants, 66 (56.9\%) experienced high/marginal food security, 34 (29.3\%) experienced low food security, and $16(13.8 \%)$ experienced very low food security. After dichotomizing the food security status, it was found that $50(43.1 \%)$ students experienced food insecurity.

\section{Food Security and Academic Performance}

There was a significant, inverse correlation between food insecurity and academic performance using a cumulative GPA. This relationship was determined by a Spearman's rho of -.216 with $p=.02$. Simple linear regression demonstrated that food security (categorical) was a significant factor associated with GPA $(\mathrm{p}=0.041)$. Multivariate linear regression revealed that food security remained to be a significant factor negatively associated with academic performance $(\mathrm{p}=0.042)$ after controlling for age, gender and race/ethnicity.

\section{Table 1}

Demographic Characteristics of Study Participants (1)

\begin{tabular}{llrr}
\hline & & $\mathrm{n}$ & $\%$ \\
\hline Gender & & 68 & 58.6 \\
& Female & 48 & 41.4 \\
& Male & 0 & 0 \\
& Other & 0 & 0 \\
& Did not identify & & \\
& & 70 & 60.3 \\
& Non-Hispanic white & 17 & 14.7 \\
& Hispanic & 7 & 6.0 \\
& Asian & 5 & 4.3 \\
& African American & 2 & 1.7 \\
& Other & 15 & 12.9 \\
& More than one & & \\
& & 3 & 2.6 \\
Year in College & 40 & 34.5 \\
& Freshman & 41 & 35.3 \\
& Sophomore & 21 & 18.1 \\
& Junior & 10 & 8.6 \\
& Senior & 1 & .9 \\
5th Year & & \\
Graduate & 108 & 93.1 \\
& 4 & 3.4 \\
Age & 2 & 1.8 \\
& 18-25 & 2 & 1.7 \\
26-29 & & \\
30 and over & 4 & 3.4 \\
Unreported & 15 & 12.9 \\
Grade Point Average (GPA) & 48 & 41.4 \\
& 1.6-2.0 & 26.7 \\
2.01-2.5 & 18 & 15.5 \\
\hline 2.51-3.0 & &
\end{tabular}


Simon, A., Goto, K., Simon, A., Breed, J., Bianco, S. / Californian Journal of Health Promotion 2018, Volume 16, Issue 1, Pages 73 -

78 .

Table 2

Demographic Characteristics of Study Participants (2)

\begin{tabular}{|c|c|c|c|}
\hline & & $\mathrm{n}$ & $\%$ \\
\hline \multicolumn{4}{|c|}{ Employment } \\
\hline & Paid Job/Internship & 49 & 42.2 \\
\hline & Unemployed & 67 & 57.8 \\
\hline \multicolumn{4}{|c|}{ Campus Involvement } \\
\hline & $\begin{array}{l}\text { Greek Life } \\
\text { Associated }\end{array}$ & 13 & 11.2 \\
\hline \multirow[t]{6}{*}{ Students } & & 3 & 2.6 \\
\hline & Athletics & 16 & 13.8 \\
\hline & Clubs & 16 & 13.8 \\
\hline & Other & 2 & 1.7 \\
\hline & More Than One & 17 & 14.7 \\
\hline & None & 49 & 42.2 \\
\hline \multicolumn{4}{|c|}{ Food Security (3 levels) } \\
\hline \multicolumn{2}{|c|}{ High/marginal Food Security } & 66 & 56.9 \\
\hline \multicolumn{2}{|c|}{ Low Food Security } & 34 & 29.3 \\
\hline \multicolumn{2}{|c|}{ Very Low Food Security } & 16 & 13.8 \\
\hline \multicolumn{4}{|c|}{ Food Security (2 levels) } \\
\hline \multicolumn{2}{|c|}{ Food Secure } & 66 & 56.9 \\
\hline \multicolumn{2}{|c|}{ Food Insecure } & 50 & 43.1 \\
\hline \multicolumn{4}{|c|}{ Participation } \\
\hline \multicolumn{2}{|l|}{ WIC } & 1 & .9 \\
\hline \multicolumn{2}{|c|}{ Donations } & 9 & 7.8 \\
\hline \multicolumn{2}{|c|}{ SNAP/ CalFresh } & 8 & 6.9 \\
\hline \multicolumn{2}{|c|}{ Private Orgs } & 2 & 1.7 \\
\hline \multicolumn{2}{|c|}{ More Than One } & 2 & 1.7 \\
\hline \multicolumn{2}{|l|}{ None } & 94 & 81 \\
\hline
\end{tabular}

Food Security and Food Assistance Program Participation

Overall, $19 \%$ of the study participants reported participating in food assistance programs in the last year. It was found that $15.2 \%$ of food secure students reported utilizing food assistance programs at some point within the last year whereas $24 \%$ of food insecure students had reported accessing those resources. Food insecurity was not significantly related to food assistance program participation. Table 3 demonstrates that $76 \%$ of food insecure students reported not utilizing any food assistance programs.

\section{Table 3}

Food Insecurity Status and Food Assistance Program Participation

\begin{tabular}{|c|c|c|c|}
\hline & $\begin{array}{l}\text { Food } \\
\text { Secure }\end{array}$ & $\begin{array}{l}\text { Food } \\
\text { Insecure }\end{array}$ & $\begin{array}{l}\mathrm{P} \\
\text { value* }\end{array}$ \\
\hline & $\mathrm{n}(\%)$ & $\mathrm{n}(\%)$ & \\
\hline $\begin{array}{l}\text { Program } \\
\text { Participation }\end{array}$ & & & \\
\hline $\begin{array}{l}\text { Yes } \\
\text { No }\end{array}$ & $\begin{array}{r}10 \\
(15.2 \%) \\
56 \\
(84.8 \%)\end{array}$ & $\begin{array}{r}12 \\
(24 \%) \\
38 \\
(76 \%)\end{array}$ & 0.229 \\
\hline
\end{tabular}

*Chi-square test.

\section{Program Participation and Campus Activity Involvement}

Students who were involved in campus activities were significantly more likely to participate in food assistance programs $(p=.04)$. Out of the students who reported being involved in campus activities, $17(25.4 \%)$ utilized food assistance programs while out of those students who were not involved in campus activities, only five students $(10.2 \%)$ utilized those resources.

\section{Food Security, Food Assistance Program} Participation and Other Factors

There was no significant association between food security status and involvement in campus activities. Additionally, gender, race and year in school were not associated with food insecurity.

\section{Food Assistance Program Participation and} Other Factors

Gender, race and year in school were not associated with food assistance program participation 
Simon, A., Goto, K., Simon, A., Breed, J., Bianco, S. / Californian Journal of Health Promotion 2018, Volume 16, Issue 1, Pages $73-$ 78 .

\section{Discussion}

The current study examined food security status and food assistance program participation among university students in northern California. The prevalence of self-reported food insecurity among study participants was $43.1 \%$. Past research revealed similar results, demonstrating that food insecurity impacts a large portion of university students (Burns, 2004; Hughes et al., 2011).

This study demonstrated that food insecurity is inversely associated with academic success. One interpretation of these results is that students who are food insecure are less likely to perform well in the classroom. This is in line with research on nutrition and cognitive development (Alaimo, 2004). Past research, which showed an inverse relationship between food insecurity and academic performance, suggests food insecurity may act as a psychological or emotional stressor, contributing to poor academic performance (Patton-Lopez et al., 2014). Our finding demonstrates the importance of developing and implementing university-level policies and programs that help students combat food insecurity.

It was found that only $24 \%$ of food insecure students utilized food assistance programs. Whether due to stigma or lack of knowledge of these resources, students who could benefit from these programs are not using them. As depicted in Alaimo's (2005) conceptual model of food insecurity, the utilization of food assistance programs could resolve most food insecurity issues.

To combat food insecurity among university students there is a need to explore strategies for enhancing food assistance program participation among food insecure students. Our study demonstrated that there was a significant relationship between campus involvement and food assistance program participation. Students who are involved on campus may learn more about food assistance programs and how to access those resources. If students learn about these programs and are encouraged to use them by other students, they may be more likely to do so.

There are several limitations in this study. First, the sample size was small and the study was conducted in one rural area in northern California. This study was also based on selfreported data, which may contain some biases. The current study was cross-sectional, which means that the authors were unable to see if those who experienced food insecurity were able to resolve the situation through the assistance of programs. Additionally, the cumulative GPA was used to measure academic performance regardless of year in college. Lastly, all data were self-reported, which contributes to recall bias.

\section{Conclusion}

Overall, this pilot study provides empirical evidence that food insecurity is inversely associated with academic success. This finding provides a rationale for addressing food insecurity issues among university students in order to foster their academic and professional success. University-level policies and programs that help students combat food insecurity, such as mandatory presentations about food assistance programs for clubs and campus organizations or access to enrollment counsellors on campus, need to be considered. The current study also indicates that the food program assistance participation rate is low among food insecure students. Future research should focus on factors that hinder food program assistance participation, such as the stigma related to utilizing food assistance programs, as well as a lack of knowledge of or access to existing assistance programs. Finally, intervention studies focusing on program assistance participation may help better understand its effects on food security in this population. 
Simon, A., Goto, K., Simon, A., Breed, J., Bianco, S. / Californian Journal of Health Promotion 2018, Volume 16, Issue 1, Pages 73 78 .

\section{References}

Alaimo, K. (2005). Food insecurity in the United States: An overview. Topics in Clinical Nutrition, 20, 281-298.

Anderson, S.A. (1990). Core indicators of nutritional state for difficult-to-sample populations. Journal of Nutrition, 120(11S), 1559-1599.

Bickel, G., Nord, M., Price, C., Hamilton, W., \& Cook, J. (2000). Guide to measuring household food security. United States Department of Agriculture. 2000. Accessed July 20, 2017. http://www.fns.usda.gov/sites/default/files/FSGuide.pdf

Blumberg, S. J., Bialostosky, K., Hamilton, L. W., \& Briefel, R. R. (1999). The effectiveness of a short form of the household food security scale. American Journal of Public Health, 89(8), 1231-1234.

Burns, C. (2004). A review of the literature describing the link between poverty, food insecurity, and obesity with specific reference to Australia. Melbourne: VicHealth.

Giedd, J.N. (2004). "Structural magnetic resonance imaging of the adolescent brain." Adolescent Brain Development: Annals of the New York Academy of Sciences, 1021, 77-85.

Hughes R, Serebryankikova I, Donaldson K, \& Leveritt M. (2011). Student food insecurity: The skeleton in the university closet. Nutrition and Dietetics, 68(1), 27-32.

McLaughlin, K.A., Green, J., Alegria, M., Costello, E., Gruber, M.K., Sampson, N.A., \&

Kessler, R.C. (2012). Food insecurity and mental disorders in a national sample of U.S.

adolescents. Journal of American Academy of Child and Adolescent Psychiatry, 51(12), 1293-1303.

Patton-Lopez, M.M., Lopez-Cevallos, D.D., Cancel-Tirado, D.I., \& Vasquez, L. (2014). Prevalence and correlates of food insecurity among students attending a midsize

rural university in Oregon. The Journal of Nutrition Education and Behavior, 46(3), 209-214.

US Department of Agriculture ERS (2015). Overview: Definitions of Food Security. Accessed July 20, 2017. http://www.ers.usda.gov/topics/food-nutrition-assistance/food-security-in-theus/definitiohttp://www.ers.usda.gov/topics/food-nutrition-assistance/food-security-in-theus/definitions-of-food-security.aspx.

Author Information

Corresponding author

Keiko Goto, PhD

Center for Healthy Communities

California State University, Chico

400 West $1^{\text {st }}$ St. Chico, CA 95929.

kgoto@csuchico.edu 